\title{
Early Intervention Services: Effectively Supporting Māori Children and Their Families
}

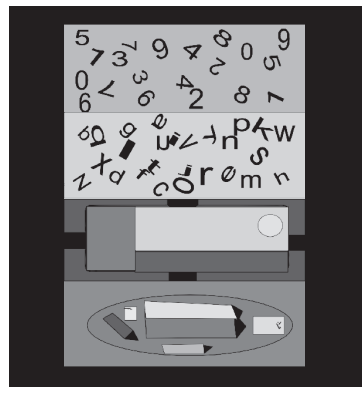

Mere Berryman and Paul Woller

Faculty of Education, University of Waikato

\begin{abstract}
This paper examines Early Intervention (EI) service provision from within one Ministry of Education region in New Zealand. It does this in order to better understand what works well and what needs to change if children from Māori families, of Early Childhood age, are to be provided with the most effective El services. By engaging with Māori families in group-focused interviews-asconversation, and then with their service providers, about their experiences of working together, researchers learned about what could provide effective services for other Māori families in similar situations.
\end{abstract}

\section{Research paper}

Keywords: Early Childhood, Early Intervention, effective services, inclusion, Māori, special education

\section{INTRODUCTION}

Evidence has shown that the earlier an action or intervention is taken in the life of a problem, or the life of the child, the more effective the action will be (Ministry of Education, 2003). In this regard, New Zealand's Ministry of Education, Special Education delivers Early Intervention (EI) services to families throughout the country. Support provided within El, as described by the Ministry of Education (2009) is:

available for children [with special needs] from the time they are born until they are settled in school. ... Special education needs are defined as those that cannot be met within a regular early childhood setting, home or family, without extra support. The need may be a physical disability, a sensory impairment, a learning or communication delay, a social, emotional or behavioural difficulty, or a combination of these. Early intervention specialists and support staff from GSE, and other providers accredited by the Ministry, work with children with moderate and severe special education needs (para. 1-3).

As part of the Ministry of Education's commitment to promoting effective services to all, including Māori families, researchers were invited by members of a Regional Management Team (RMT) to hold interviews-as-conversations in four Special Education (SE) districts within the one region. Researchers talked with Māori families who had received an El service and also with the Māori and non-Māori service providers who had worked with these families. This paper is based on the findings from these conversations during May, 2009.

\section{BACKGROUND}

Various conceptual models, traditionally developed from the viewpoint of different professional groups, have been used to explain learning and behaviour concerns associated with special needs students. The causal factors identified by each of the different professional groups are critical to the identification, assessment and intervention procedures associated with each of the models (Wearmouth, Glynn \& Berryman, 2005). Some traditional models identify the cause of behaviour disorders to be the result of psychological or biological damage or dysfunction. Traditional western models such as these often stem from a functional limitations paradigm and are characterised by the identification and reification of disabilities and special needs (Moore et al., 1999). Ecological models, in contrast, locate the problematic behaviour within the interface between the learning environment and the student (Ysseldyke \& Thurlow, 1994) and are more often associated with an inclusive paradigm.

In New Zealand, the SE 2000 policy (Ministry of Education, 1997; 1998) clearly advocated working within an inclusive paradigm through the use of interventions focused on the learning environment. Simultaneous to the introduction of this policy, a study was undertaken that aimed to identify, from an inclusive perspective, sites of effective practice for improving learning and/ or behaviour outcomes for Māori students with identified special educational needs (Berryman et al., 2002). In order to develop insights into some of the challenges and responses located within these contexts, these researchers compared international literature on students from minority cultures who had identified learning and/or behavioural needs with literature from New Zealand regarding the support systems provided to Māori students with 
similarly identified needs. These reviews provided some clear indicators of effective practice when working in a range of settings with minority groups. Although there were distinct cultural differences, there were a surprising number of problems and solutions held in common, perhaps in part due to the common colonial education experiences. Common indicators of effectiveness included the importance of team approaches. Clearly, teams were more effective when they were built on a basis of collaboration and reciprocity, where the expertise of parents/caregivers and family members not only informed the work of the professionals but were also extended by the knowledge and expertise of professionals. A common means of overcoming problems, therefore, was understood to be the development of a clear understanding of what excellence in these contexts might look like from both the families' and the professionals' perspectives.

Using a process of triangulation, Berryman et al., (2002) identified five sites that demonstrated effective interventions for Māori students with identified special needs. Researchers worked with Māori elders throughout the project, also meeting twice with an advisory group of special education professionals who were asked to reflect on and contribute to the findings. Five collaborative stories revealed that family members had made valid and worthwhile contributions and were readily able to theorise these experiences. Within an inclusive ecological paradigm, the professionals had listened to and worked collaboratively with families, taking careful account of the range of influencing factors within the settings in which these children engaged.

A direct consequence of this strategy was that the relationship between family members and professionals had developed on the basis of mutual respect for what the other could contribute. Thus, assessments at the beginning of interventions were better informed and more effective interventions could be collaboratively designed and introduced. While there was still little evidence to suggest that some of the professionals may have wanted to work within the functional limitations paradigm, Māori voices had maintained authority and prevented this from happening. The key to professionals working effectively with Māori families in this research was their ability to listen and maintain responsiveness. In this way professionals were able to understand and respect the interrelationship between cultural values and practices as the foundation for working in ways that were interdependent, respectful and collaborative (Berryman et al., 2002).

More recent research from Te Kotahitanga by Bishop, Berryman, Cavanagh and Teddy (2007) also identifies the importance of relationships and responsive pedagogy to the engagement of Māori students in secondary school classrooms. These researchers describe a 'culturally-responsive pedagogy of relations' as being one in which:

Educators can create learning contexts that will address the learning engagement and improve the achievement of Māori students by developing learning-teaching relationships where the following notions are paramount, that is:

- where power is shared: learners' right to self determination

- where culture counts: learners can bring who they are

- where learning is interactive and dialogic: ako

- where connectedness is fundamental to relations

- where there is a common vision: an agenda for excellence for Māori education (p. 15).

The importance of culturally-responsive practitioners was also recognised by the Ministry of Education: Special Education and outlined in the framework "Te Hikoitanga: Pathway to Success." Te Hikoitanga defines responsive services:

as those that take a Māori potential approach by acknowledging the right of tamariki [children] and whānau [families] to help determine the best service outcomes for them. Services such as these are accessible, of high quality, are culturally relevant, and flexible enough to meet the diverse realities of tamariki [children] and whānau [families] (Ministry of Education, 2008).

In part, the research undertaken in these El sites and discussed in this paper aimed to test the relevancy and validity of these previous findings within El settings.

\section{THE RESEARCH PROJECT}

\section{Method}

In this present study El service providers introduced the opportunity for families to talk with researchers about their experiences. Two researchers then engaged with groups of volunteers in a participatory exercise focused on the influence of El services for Māori families. This involved four group-focused, in-depth, semi-structured, interviews-as-conversations (Bishop, 1996) with Māori families and later, four group-focused interviews with the El providers with whom they had worked. First, researchers explained the research in detail and responded to any researchfocused, participant questions. Researchers sought 
to ensure that all participants understood that they were free to decline to answer questions and that they could elect to withdraw sections from their transcribed interviews or withdraw from the project at any stage without disadvantage. Then, depending upon whether researchers were speaking with family members or El providers, they posed the following research question: "In your experience how has the El service been effective for you/Māori?" This was followed by a set of general questions used to further prompt participants' reflections.

These conversations explored the attitudes, feelings and beliefs of people in regards to their own experiences with the El service, whether they had provided it or received it. Researchers listened to participants' experiences and taped their stories. By talking with these people, researchers aimed to facilitate their reflections on the relationships and processes they had collectively engaged with. Interviews provided a detailed participant picture of what was occurring in terms of the El services for Māori in each of the four districts. From the interview data and process the researchers were able to tentatively identify the specific elements that participants themselves consistently understood as contributing to the success of their engagements.

Transcribing and returning transcripts to participants to verify and add any additional annotations happened at each district office. Researchers who had undertaken the interviews then analysed all transcribed material to test the previously identified specific elements. They compared results and then undertook an electronic word count to check for frequency of the mention of the agreed elements/themes. Researchers also categorised subthemes using the electronic word count facility. Selected quotes from the transcribed interviews were then used to highlight some of the common experiences represented within the identified themes. Themes emerging from participants' experiences were also used to address the research questions and report back at a district and regional level.

\section{RESULTS}

A total of 23 family members and 29 El providers from the four districts were interviewed. The analysis of the transcripts, as discussed above, highlighted the following three major themes:

1. Participants' understandings about El.

2. Two common elements of effective EI practices.

3. Challenges regarding effective El practices.

These themes are discussed below and exemplified by participants' experiences.

\section{Participants' understandings about El}

Family members and El providers across the four districts shared very similar understandings. They talked about El providing hands-on, family-focused support that was accessible, timely and responsive.

[The El providers] have been awesome. They call in whenever I need them. If I am stuck and not knowing something then they are there. I have meetings with 'Strengthening Families' and they are there. (Family member 2, District 2)

El providers said they worked holistically and as part of a team to help families. They understood that advocating on behalf of families and supporting staff members in education centres were important aspects of their role.

We would work with the children and their families at home and in their community settings. (Provider 1, District 3)

Family members and El providers both understood that the earlier issues were identified the more effective the interventions were likely to be. They also understood that effective assessment needed to precede interventions if they were to benefit the child.

[The role of El is] identifying issues early [and] providing services at an early age which is going to have more impact on the child. [There is a] strong belief in working and supporting children as early as possible. (Provider 1, District 4)

Family members spoke about the role that EI providers played in working with and 'normalising' the potential of their children.

If we had friends and family come over, they were speaking to him so slowly. It was agonising watching people. But [El providers] were the people that just spoke to him like he was normal, like there was nothing wrong. (Family member 4, District 3)

El providers also discussed the important focus on potential.

Helping parents see glimpses of potential. With lots of our behaviour cases, the parents actually don't often see the positives in the children, and so getting down on the floor and playing and pointing out some of those positives actually goes a long way to them starting to re-frame their own relationship with their children and then that can be motivating [for families] to then do the ongoing parts of intervention without hard work. (Provider 5, District 3) 
El providers suggested that once families recognised the potential in their child it gave everyone greater focus and something that they were able to strengthen collaboratively.

\section{Two common elements of effective El practices}

Family members and service providers also talked about how, in their own experiences, El had been effective for Māori. Again, both groups provided very similar responses. The two highest and strongly interconnected priorities were the importance of developing respectful relationships of trust, while working in ways that were responsive to the families' needs, aspirations and culture. Both groups understood that the development of relational contexts such as these were more likely to result in the input from each group being valued by the other and the work being able to proceed collaboratively and interdependently. Thus each group was able to contribute more effectively and with greater confidence to the goal of realising the child's potential.

\section{Respectful relationships of trust}

The establishment of respectful relationships was seen as foundational to successful interventions. Each group described these relationships as nonjudgemental and reciprocal. Relationships such as these helped each party begin to trust and value the input of the other.

It's that respect for each other and they can ring me up and pop around and talk freely and it's like there's been no judgement being a single young Māori mother or anything like that. I've had such great dealings with [EI providers], it's the fact that they're respectful of myself and my individual story, that's why I praise them so highly and they've done everything possible to support me in every venture I've taken. (Family member 9, District 3)

The most important part is to establish trust with the families and empowering the families to feel part of the team around the child. Then you get much better assessment information in the range of settings the child is in and you get long-term buy-in if you have spent that time in the engagement phase in that relationship. Our role is to provide advice and guidance as well as assessment and programming but that is all reliant on how you are perceived by the family you work with. So you can have the best plan/assessment in the world but if you haven't got family buy-in a lot of what you have done is wasted in a way. (Provider 3, District 1)
Many family members talked about the importance of providers who showed genuine care and interest in their child.

I think the biggest thing that struck me is that I feel that they genuinely love [the child] and they genuinely care about what is happening with him, whereas with a lot of the other medical people that we see, it is just in and out the office, saying "Thank you. Bye". And I feel that I can contact [service providers] any time that there is a problem and they respond pretty much straight way. (Family member 5, District 3)

Service providers also stressed the importance of establishing good relationships before any intervention could even begin to take place.

You need to develop the relationship before anything else can go anywhere. (Provider 3, District 3)

Both groups understood that connecting at a personal level before they connected at a professional level was essential; however, they cautioned that this process took time.

Usually with my visits, it may involve just a cup of tea and talking and I think this is where we're in conflict with Ministry processes that we don't always do what we're meant to do and get the service agreement signed and the consent form and all of that started straight way. We just need time to actually establish a relationship and that first visit might be just a cup of tea and talking together and then subsequent visits, you start doing a little bit, but definitely not in the first visit. (Provider 1 , District 3)

Many family members identified this as the important point of difference between the EI service they had received from their provider and what they experienced as the impersonal and more 'threatening' service offered by some other organisations.

You go to some meetings at the hospital to see a doctor [and] there is a set criteria, you've got to do this, you've got to do that. With [service providers], you are relaxed. You just don't have to follow one lead, it all flows in. The atmosphere is totally different. (Family member 6, District 3)

\section{Culturally responsive ways of engaging}

Relationships of trust and respect provided the important foundation upon which each group, family and provider, believed the actual El work could begin. This required effective listening and learning from each other. 
The service has been really important because sometimes it is about a friendly face, a person that is easy to talk to, where you could tell them things because you are worried about your child and they can say, "Well, this is what you do if you have to refer to us". If I didn't have that person that I could talk to, to tell me what I should do and where I should go, then we would probably be, as a family, really lost along the way. (Family member 8, District 3)

Family members appreciated service providers who respected and understood the importance of their own cultural identity.

They've all been very supportive of the fact that I'm Māori and always put that into consideration of everything and any venture we've taken. I don't really know how to explain it; they seem like they're aware of Māori but sort of just 'get it' especially dealing with me because I have such a large whānau and discuss it with them a lot. They've all been really supportive of that. I think it's just been so casual for me and I've had it so easy, I've never really had to think about it. (Family member 9, District 3)

Furthermore, family members were impressed by the ease with which service providers acted in regards to their culture.

A lot of times, it is just the little things like just taking your shoes off at the door and things like that. And it was done easily. It wasn't like they kind of got to the door and, "Oh, that's right, l'd better take my shoes off because I'm in a Māori house". They just did it. It is just part of what they do. (Family member 5 , District 2)

El providers talked about the importance of not just rushing in as the expert but giving people time to figure out who they were and where they were coming from.

It is also just some of the training that we have had to be more aware of just how to behave and how to talk and what to say and how to listen and not to come in saying, "Right, this, this and this to do" and you are thinking, "Right, I need to get that sort of thing done" and it is taking your time and letting people try and get an idea of who you are and what you are doing here anyway. (Provider 2, District 2)

Many attributed this to the role of the Kaitakawaenga or cultural advisor within their Special Education teams.

We tended to arrive [in Māori families' homes] with our particular fears and think, "Well, we've got to do that," whereas now with our Kaitakawaenga ... we know we have a lot more time [because] she has spent that time to develop that relationship first. I think that was our protection. If we didn't have someone else to go with, we went with our list and just ticked it off. (Provider 3, District 3)

\section{Challenges regarding effective EI services for Māori}

The final major theme was related to the challenges that emerged around the provision of El services for Māori. Importantly, the number of responses from each group about the challenges regarding El were minimal when compared to the number of responses concerned with what participants thought was effective about El service provision. In the main, challenges revolved around the complexity of cases and issues to do with resourcing and time. For a few families, transition to school when children would no longer be seen by El providers was a concern, as was the lack of Special Education resourcing in Māori medium settings. Only one family member interviewed was unhappy with the El service they had received. They believed there were unacceptable delays in having their child seen and a lack of communication from El providers.

The issues that El providers understood as restricting their ability to deliver services to Māori families were mainly resource-related. They included the mismatch between the time required to establish relationships with Māori families as opposed to case-work guidelines and the lack of Māori staff to provide cultural support to nonMāori staff.

One of the key issues is that we are a Ministrydelivery service and there are some prescribed limits around the sort of work that we do that doesn't necessarily always fit with our holistic, early intervention approach to all our families. From an organisational view, we need to have acknowledgement that we need that flexibility. (Provider 8, District 2)

\section{DISCUSSION AND CONCLUSION}

It is clear from the analysis of the interviews that Māori family members and service providers were in general agreement about what effective EI practices for Māori looked like. Both groups also had some common understandings about what they saw as the challenges regarding effective $\mathrm{EI}$ for Māori. These themes were articulated by Māori family members and service providers from all four districts with only minor variations. 
Across the region participants saw the role of El as providing an effective family-focused service that provided support and guidance in times of need. Early intervention was described by family members and service providers working holistically with the family as part of a team around the child. In line with Berryman et al., (2002), a team approach in which parents, cultural experts, and professionals collaborate to define needs and address them is most effective when the expertise of family members informs and guides professionals, and is extended by the professionals involved. Practices that follow these guidelines have been termed 'culturally-responsive', meaning that family members should be able to bring "who they are" or their cultural identity into any planned intervention (Bishop, Berryman, Tiakiwai, \& Richardson, 2003). The experiences of these families and professionals also demonstrated the sharing of power and the fundamental importance of establishing relationships before engaging in the intervention or working towards the common vision (Bishop et al., 2007).

Although families and El providers were challenged by the complexity of some cases, El providers understood the need to maintain a focus on the child's potential and on what they could achieve, rather than being overwhelmed by the challenges. This involved their ability to: share skills and knowledge with the family; coordinate multiple services; and be aware of the big picture involved for the child and the family. Professionals were able to do this by establishing relationships with family members and working in ways that were culturally-responsive and seen to be appropriate in cultural terms. They began their work by first getting to know members of the family and developing two-way relationships. In this, they were respectful of the knowledge families had about their own children and the skills they brought with them into the working relationship. They then sought to bring their own professional skills into their work with families in ways that were respectful, interdependent and responsive. These relational actions have real implications for other professionals seeking to work more effectively with Māori.

\section{REFERENCES}

Berryman, M., Glynn, T., Walker, R., Reweti, M., O'Brien, K., Boasa-Dean, T., Glynn, V., Langdon, Y., \& Weiss, S. (2002). SES sites of effective special education practice for Māori 2001. Draft report to the SES Board and Executive Team. Specialist Education Services.

Bishop, R. (1996). Whakawhanaungatanga, collaborative research stories. Palmerston North: Dunmore Press.

Bishop, R., Berryman, M., Cavanagh, T., \& Teddy, L. (2007). Te Kotahitanga Phase 3 Whanaungatanga: Establishing a culturally responsive pedagogy of relations in mainstream secondary school classrooms. Report to the Ministry of Education. Wellington: Ministry of Education.

Bishop, R., Berryman, M., Tiakiwai, S., \& Richardson, C. (2003). Te Kotahitanga: Experiences of year 9 and 10 Māori students in mainstream classrooms. Final Report to the Ministry of Education. Wellington: Ministry of Education.

Ministry of Education. (1997). Special Education 2000. Wellington: Ministry of Education.

Ministry of Education. (1998). Special Education 2000 update. Wellington: Ministry of Education.

Ministry of Education. (2003). Church Report - The Definition, Diagnosis and Treatment of Children and Youth with Severe Behaviour Difficulties. Wellington: Ministry of Education.

Ministry of Education. (2008). Te Hikoitanga Māori Cultural Responsivity Framework. Retrieved 1 September, 2009 from http://www.minedu. govt.nz/NZEducation/EducationPolicies/ SpecialEducation/PolicyAndStrategy/TeHikoitanga MāoriCulturalResponsivity.aspx

Ministry of Education. (2009). Early intervention services and support. Retrieved 1 October, 2009 from http://www.minedu.govt.nz/NZEducation/ EducationPolicies/SpecialEducation/ForParents/ EarlyInterventionServicesAndSupport.aspx

Moore, D., Anderson, A., Timperley, H., Glynn, T., Macfarlane, A., Brown, D., \& Thomson, C. (1999). Caught between stories: Special education in New Zealand. Wellington: New Zealand Council for Education Research.

Wearmouth, J., Glynn, T., \& Berryman, M. (2005). Perspectives on student behaviour in schools: Exploring theory and developing practice. London: Routledge Falmer.

Ysseldyke, J., \& Thurlow, M. (1994). What results should be measured to decide whether instruction is working for students with disabilities? In J. Ysseldyke and M. Thurlow (Eds), Educational Outcomes for Students with Disabilities. Minnesota: The Haworth Press. 


\section{AUTHORS' PROFILES}



Mere Berryman is currently a senior research fellow at Waikato University in New Zealand, where she is the Professional Development Director of Te Kotahitanga.

EMAIL

mere@waikato.ac.nz

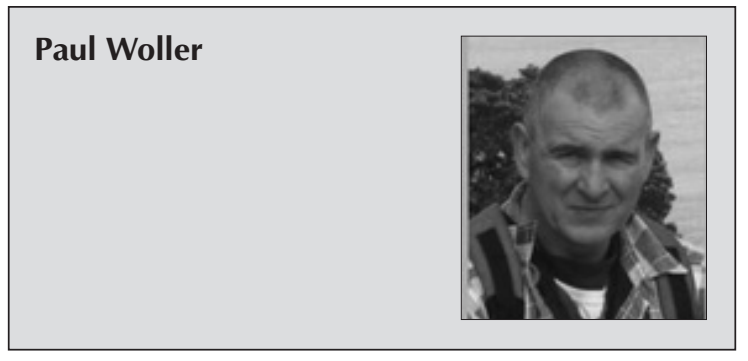

Paul Woller is a Waikato University employee who is currently the Project Coordinator for He Kākano, a professional development programme for school leaders.

EMAIL

prwoller@waikato.ac.nz 